\title{
EXPERIMENTAL STUDY OF THERMAL EFFECT ON OLIVE WOOD POROUS STRUCTURE DURING CARBONIZATION
}

\author{
Najla Grioui ${ }^{1}$, Kamel Halouani $^{1}$, André Zoulalian' ${ }^{2}$ Foued Halouani ${ }^{3}$
}

\begin{abstract}
The study presented in this paper is an investigation on the porosity changes induced by the carbonization of Tunisian olive wood. The porosity is measured by mercury porosimetry. The experimental results show that the total porosity of carbonized wood increases with the temperature. It should be underlined that the formation of some macropores during the increase of the temperature is certainly due to the breaking of the cell wall by the mercury penetration. The weakness of the cell wall is observed when the degradation rate of the three pseudo components of wood, the notion of which has been introduced by the authors in a previous article [Grioui et al. 2006], becomes high which corresponds to the temperature range between $523 \mathrm{~K}$ and $548 \mathrm{~K}$.
\end{abstract}

Keywords: mercury porosimetry, porous structure, olive wood, carbonization.

\section{INTRODUCTION}

Modeling wood carbonization needs the knowledge of several thermo-physical properties of the material: density, thermal conductivity, permeability, porosity and heat capacity. Indeed, the variation of thermo-physical properties of wood during its thermal degradation is due to the modifications of the structure, the result of which is a variation of the porosity. In fact, the porosity has not only an important role in heat and mass transfers inside solid matrix during the carbonization but it also affects the mechanical properties of wood. In the same way, the knowledge of porous distributions structure permits to evaluate by elaborated correlations some properties such as the thermal conductivity [Thunman and Lecker, 2002 ] and permeability [Fujii et al.1997].

The characterization of porous solids is described in the literature [Moscou and Lub, 1981; Mackay and Roberts, 1987] and various techniques are used to measure the porosity. Mercury porosimetry, gas adsorption, calorimetry, thermoporosimetry and electron microscopy have been used [Leofanti et al. 1998].

Mercury porosimetry is a commonly used method for the porosity characterization of several materials studied such as wood [Blankenhorn et al. 1978; Klose and Schinkel, 2002], coal [Klose and Schinkel, 2002; Clarkson and Bustin, 1999] catalysts [Rigby et al. 2003], and is widely accepted as a technique of measurement of the total pore volume and the pore size distribution in the macro- and mesopore ranges [Leon, 1998]. It is often the method that is chosen, particularly in the industry [Rigby and Edler, 2002]. It has remained popular mainly because the apparatus is commercially available from a number of suppliers and it is one of a very few techniques with which it is relatively straightforward to probe size over at least 3 to 4 orders of magnitude using only one method [Kumar and Gupta, 2003].

\footnotetext{
${ }^{1}$ Micro-Electro-Thermal Systems - Industrial Energy Systems Group (METS-IESG)

Institut Préparatoire aux Etudes d'Ingénieurs de Sfax (IPEIS) B.P: 805 - 3019, Sfax - Tunisie Najla.Grioui@fss.rnu.tn and Kamel.Halouani@ipeis.rnu.tn

${ }^{2}$ Laboratoire d'Etudes et de Recherches sur le Matériau Bois (LERMAB). Université Henri Poin carré Nancy 1 (UHP), B.P : 239- 54506 Vandoeuvre lès Nancy Cedex- France. Andre.Zoulalian@lermab.uhp-nancy.fr

${ }^{3}$ Ecole Nationale d'Ingénieurs de Sfax (ENIS), B.P : 3038, Sfax - Tunisie. Foued.Halouani@enis.rnu.tn

Corresponding author: Andre.Zoulalian@lermab.uhp-nancy.fr

Received: April 7, 2006. Accepted: September 16, 2006
} 
Mercury porosimetry has been used for the first time by Trenard 1980, in order to measure the dimensions and volumes of cavities for different wood species (beech, spruce, scotch pine and fir). Trenard 1980, realized these experiments on microsections samples and then on $10 \mathrm{~mm}$ longitudinal direction for massif wood samples. His experimental results have permitted him to describe preferential flow paths of mercury inside wood material and their distribution in wood. The results obtained by this technique are compared with microscopic observations. Laurent and Trenard, 1981 have used mercury porosimetry to study virgin beech wood. They concluded from their experimental data concerning virgin beech wood that there are several directions for the mercury penetration. Most of the mercury penetrates into elements having pores between 10 and $100 \mu \mathrm{m}$ which correspond to vessels, the secondary path range respectively between 1 to $4 \mu \mathrm{m}$ and 0,1 to $0,2 \mu \mathrm{m}$ corresponds to fibers and their punctuations. A last mercury penetration path is observed for pores, lower than $0,03 \mu \mathrm{m}$, the size of which corresponding to the micropores through the walls themselves. Mercury porosimetry has also been used by Randall and Blankenhorn, 1982 to investigate total porosity of wood, real density, apparent density and pore size distribution. They showed that total porosity and heat of combustion increase with the final temperature of carbonization. They also showed that the pore size distribution changes with increasing temperature. They concluded that the evolution of pore size distribution is realized in the carbonization process between $523 \mathrm{~K}$ and $673 \mathrm{~K}$ for hardwoods and between $523 \mathrm{~K}$ and $573 \mathrm{~K}$ for southern yellow pine. Kumar and Gupta, 1993 realized their experiments for cubic wood samples (size $<15 \mathrm{~mm}$ ) of Acacia and Eucalyptus by carbonizing them at temperatures between 673 and $1473 \mathrm{~K}$ under different heating rates, a slow one (about $\left.4{ }^{\circ} \mathrm{C} \cdot \mathrm{min}^{-1}\right)$ and fast ones $\left(20,43,80\right.$ and $\left.174{ }^{\circ} \mathrm{C} \cdot \mathrm{min}^{-1}\right)$. They showed that the porosity of wood depends on the conditions of carbonization. However, they concluded from their experiments under slow carbonization and for the wood chars produced from Acacia and Eucalyptus, that the porosity increases with the carbonization temperature up to $1273 \mathrm{~K}$ and after, its value is nearly constant. They interpreted this results by the release of volatile matter which results in an overall opening up of the structure. When, the temperature reached about $1273 \mathrm{~K}$, the contribution of volatile release to create a new pores becomes very small and breakage of crosslinks and micro crystallite alignment resulting in the loss of porosity become significant. For the wood chars produced by fast carbonization, the porosity increased progressively with carbonization temperature. It is due to two factors: the release of volatile matter and the formation of cracks and voids. Kumar and Gupta, 1993 prolonged soaking at carbonization temperatures of 1073 and $1273 \mathrm{~K}$. They found that wood samples carbonized slowly have a lower porosity than the ones fast carbonized. They also achieved their study by the influence of wood species and showed that the Eucalyptus wood chars particularly produced under slow carbonization conditions have lower porosity and a higher apparent density than Acacia wood chars produced under identical carbonization treatment. Mackay and Roberts, 1993 concluded that the increase of temperature rises the shrinkage of material structure. Recently, mercury intrusion method has been used to measure pore structure and a mathematical model has been developed by Klose and Schinkel, 2002 based on population balance and mass balance. This model considers particle shrinkage, different kinds of new pores ignition, and the coalescence of pores. This model is in well agreement with the experimental data.

The aim of the present work is to measure and analyze the change in density, porosity and pore size distribution of virgin and carbonized olive wood. The experimental data are also requested to establish the development of pore size distribution as a function of final carbonization temperatures. Thermobalance was used to carbonize olive wood samples at a fixed final temperature between $473 \mathrm{~K}$ and $623 \mathrm{~K}$. A mercury porosimeter was used to measure density, porosity and pore size distribution changes over final carbonization temperatures up to $623 \mathrm{~K}$. 


\section{MATERIALS AND METHODS}

\section{Material and sampling}

All our samples are cut from hard olive wood, the origin of which is located in the region of Sfax, Tunisia. Table 1 shows the elemental analysis which has been realized at the Central Service of Analysis of the CNRS in France. By neglecting the sulphur and nitrogen fractions, the empirical formula of this wood obtained from the above analysis data is $\mathrm{CH}_{1,67} \mathrm{O}_{0,75}$. The carbonized olive wood samples utilized later were prepared from rectangular plates samples of olive wood, the dimensions of which are $15 \times 6 \times 2.5$ $\mathrm{mm}$. The carbonization of the samples is realized at fixed temperature in a thermobalance with an argon flow rate fixed at $7.2 \mathrm{litre} / \mathrm{h}$ (measured at $293 \mathrm{~K}$ under atmospheric condition). The experiments start with a drying session during which, the temperature is raised from room temperature to $423 \mathrm{~K}$ with a heating rate of $20 \mathrm{~K} \cdot \mathrm{min}^{-1}$. When $423 \mathrm{~K}$ is reached, a holding time of $20 \mathrm{~min}$ is used. Then, the same heating rate is applied to the device until reaching the fixed studied temperature (pre-heating phase), comprised between 473 and $623 \mathrm{~K}$. This protocol has been chosen in order to attain the isothermal stage for wood pre-heating without any intra-particle gradient and in order to limit the first thermal dynamic stage [Koufopanos et al. 1989]. The subsequent thermal decomposition is carried out in isothermal conditions during 5 hours. The same experiment is repeated for fixed temperatures range between 473 and $623 \mathrm{~K}$. The residual mass curves of olive wood samples, for the six studied temperatures ( $T=498 ; 523 ; 548 ; 573 ; 598$ and $623 \mathrm{~K}$ ), presented on figure 1 , show that the rate of the degradation kinetics increases with the temperature. At high temperatures (598 and $623 \mathrm{~K}$ ), a very fast mass loss rate is observed and very rapidly the reduced residual mass becomes constant. At $623 \mathrm{~K}$, the residual mass represents $32 \%$ of the initial dried mass of the sample.

Table 1: Elementary composition of Tunisian olive wood.

\begin{tabular}{|c|c|}
\hline Elementary composition & Mass fraction (\%) \\
\hline Carbon & 45.08 \\
\hline Hydrogen & 6.21 \\
\hline Nitrogen & 0.4 \\
\hline Oxygen & 45.39 \\
\hline Sulphur & below 0.3 \\
\hline
\end{tabular}




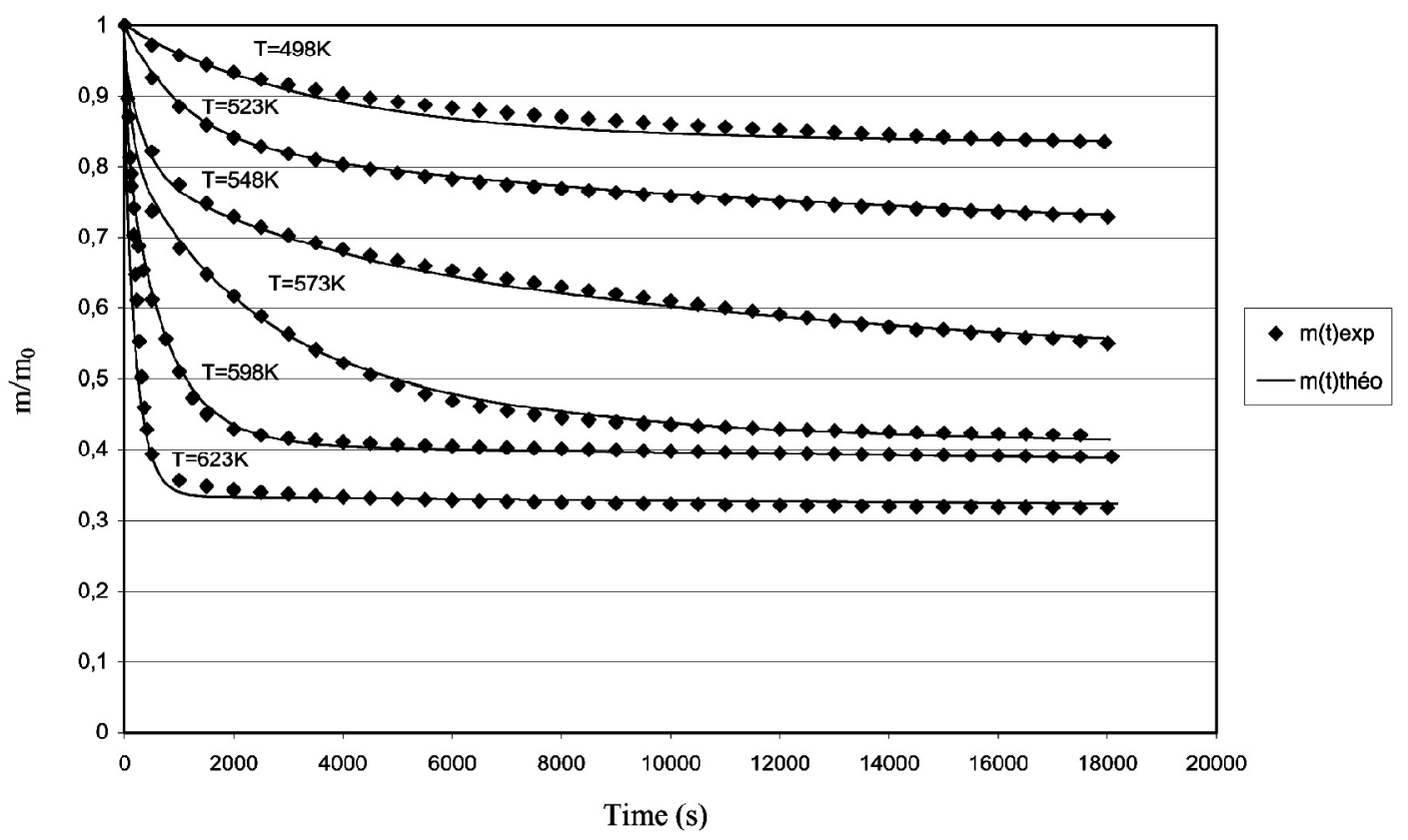

Figure 1: Experimental reduced residual mass of olive wood during carbonization at different studied temperatures

The study of the porosity on carbonized olive wood samples will be realized on the samples obtained at the end of the isothermal carbonization. For each fixed temperature, the experiments are repeated three times and the results given later in the tables and figures correspond at the average values of the three samples. We observed a good reproducibility during carbonization experiments and porosimetry measurements. The deviation between experimental curves in the same conditions does not exceed $5 \%$.

\section{Mercury porosimetry} Apparatus

Two porosimeter devices, Pascal 140 and Pascal 240, were used to measure the porosity. Pascal 140 working at moderate pressure from $20 \mathrm{~Pa}$ up to $400 \mathrm{kPa}$ allows to characterize macropores (radius between 1.9 and $58 \mu \mathrm{m}$ ). Pascal 240 was used to determine the micropores distribution (radius between $3.7 \leftrightarrow 10^{-3}$ and $0.01 \mu \mathrm{m}$ ) with pressure varying from 0.1 to $200 \mathrm{MPa}$. The main parts of the two Pascal 140 and 240 are: a dilatometer containing the sample to analyze, a pressurization system including the gear pump for the air, a depressurization system forming the gear pump for the air and an other one for the vacuum, a system measuring the volume and the pressure of mercury permitting to determine mercury intrusion into the sample and intrusion pressure. Porosimeters Pascal 140 and Pascal 240 are coupled with a numerical station to acquire and memorize experimental data.

\section{Principle}

Mercury porosimetry is based on the non-wetting property of the mercury for most materials and for an external pressure imposed. The basic mercury porosimetry experiment consists in increasing the imposed pressure with small increments and in measuring the volume of mercury entering into the 
sample during each pressure increment. The relationship between the imposed pressure and the pore size is described by Washbun equation [Washburn 1921] assuming that the pore is cylindrical:

$$
r=\frac{-2 \gamma \cos \theta}{P}
$$

where $P$ is the imposed pressure (MPa), $\gamma$ is the mercury surface tension $\left(\gamma=480 \mathrm{mN} . \mathrm{m}^{-1}\right), \theta$ is the contact angle $\left(\theta=140^{\circ}\right)$ and $r$ is the pore radius $(\mu \mathrm{m})$. The mercury surface tension and contact angle with the solid material are assumed constant during all along the experiment. By measuring the quantity of mercury penetrating into the sample pores and the equilibrium pressure at which intrusion occurs, experimental data are obtained to calculate the pore volume distribution as a function of their radius.

The pressure being increased in a progressive way between $20 \mathrm{kPa}$ and $200 \mathrm{MPa}$, the variation of the measured penetrating volume as a function of pressure $P$ and of the capillary radius $r$ allows to obtain the mercury cumulative volume $V P T$ and the frequency of the pores distribution $f(r)$. $d r$ between $r$ and $r+d r$ for the pressure variation between $P$ and $P+d P$.

The introduced mercury volumes depend on the initial mass of the sample. The knowledge of the sample apparent density $\rho_{a}$ and the distribution of the frequencies allow to estimate the following characteristics of the sample:

- total porosity (\%):

$$
\varepsilon=\rho_{a} V P T
$$

- Total area surface $\left(\mathrm{m}^{2} / \mathrm{g}\right)$

- real density $\left(\mathrm{kg} \cdot \mathrm{m}^{-3}\right)$ :

$$
S=\frac{1}{\rho_{a}} \int \frac{2}{r} f(r) d r
$$

$$
\rho_{s}=\frac{\rho_{a}}{1-\varepsilon}
$$

- Average pore radius $(\mu \mathrm{m})$ :

$$
\bar{r}=\int r f(r) d r
$$

Knowing the initial mass sample, the porosimeter Pascal 140 can determine a value of the apparent density $\rho_{a}$ when the dilatometer is full of mercury.

\section{Procedure}

Porosimetry measurement is held in two stages. For the first stage (Pascal 140), virgin or carbonized olive wood sample is placed in the dilatometer. The gas phase is eliminated from the sample to create a relative vacuum in the pores, improving mercury intrusion (pressure is about $20 \mathrm{~Pa}$ ), the dilatometer is then filled with mercury. The mercury volume having penetrated in the olive wood sample allows the direct measurement of the total pore volume $\left(\mathrm{mm}^{3}\right)$. This measurement is obtained by a capacity system, its condenser armature constitutes an external tubular electrode fixed on the dilatometer. The second armature is mobile and consists in a mercury column inside the calibrated tube of the dilatometer. Once this step is over, we recover the dilatometer and we use the porosimeter Pascal 240. This dilatometer is then introduced into the pressurized cell then measurement can start. During this step, the pressure varies from 0.1 to $200 \mathrm{MPa}$ with a increase rate of $2221 \mathrm{kPa}^{-1} \mathrm{mn}^{-1}$. The pore size distribution can be 
investigated between $3.7 \times 10^{-3}$ and $0.01 \mu \mathrm{m}$. Values obtained by capacity system depend not only on the mercury volume introduced into the pores but also on the mercury compressibility at high pressures which can be reached by Pascal 240. Finally, a blank test is needed to take into account the influence of the compressibility of mercury on apparent volume introduced.

\section{RESULTS AND ANALYSIS}

\section{Virgin olive wood}

Figure 2 presents the pore size distribution of olive wood plotted on as a function of pore radius. Pore size distribution analysis shows a seemingly bimodal distribution for micropores and macropores. The anatomic structure of the specimen revealed by electronic microscopy confirms the existence of the micro and macropores size (Figure 3). In the growth rings, the pores are uniformly distributed and the medullar rays are numerous and well visible. As reported in the literature [Ghelmeziu and Suciu, 1959], the radius of the anatomic elements of olive wood are classified in three classes. Class I, for which the pore radius vary between $4.10^{-3} \mu \mathrm{m}$ and $0.1 \mu \mathrm{m}$, corresponds to the fine punctuations and / or cracks in the cellular membranes. Class II, for which the pore radius vary between $0.1 \mu \mathrm{m}$ and $1 \mu \mathrm{m}$, corresponds to fibers and their punctuations. Class III, for which the pore radius vary between $1 \mu \mathrm{m}$ and $100 \mu \mathrm{m}$, corresponds to the vessel and ligneous medullar rays.

A summary of the experimental data is given on table 2 . The values of the apparent density value $\left(880 \pm 40 \mathrm{~kg} \cdot \mathrm{m}^{-3}\right)$ are in agreement with the data of the literature [Ghelmeziu and Suciu, 1959]. The value of total porosity is measured with a good precision by our mercury porosimeter. From the value found for the porosity, the one of real density $\left(\rho_{s}=1572 \mathrm{~kg} \cdot \mathrm{m}^{-3}\right)$ is also in agreement with the data given in the literature for the lignin matter density $\left(\rho_{s}=1500 \pm 100 \mathrm{~kg} . \mathrm{m}^{-3}\right)$ [Ghelmeziu and Suciu, 1959].

Table 2: Parameters of virgin olive wood obtained by porosimetry measurements.

\begin{tabular}{|l|c|}
\hline Cumulative total volume VPT $\left(\mathrm{mm}^{3} / \mathrm{g}\right)$ & 500 \\
\hline Total area surface $\sigma\left(\mathrm{m}^{2} / \mathrm{g}\right)$ & 35 \\
\hline Mean pore diameter $\bar{d}(\mu \mathrm{m})$ & 0.023 \\
\hline Total porosity $\varepsilon(\%)$ & 44 \\
\hline Apparent density $\rho_{a}\left(\mathrm{~kg} \cdot \mathrm{m}^{-3}\right)$ & 880 \\
\hline Real density $\rho_{s}\left(\mathrm{~kg} \cdot \mathrm{m}^{-3}\right)$ & 1572 \\
\hline
\end{tabular}




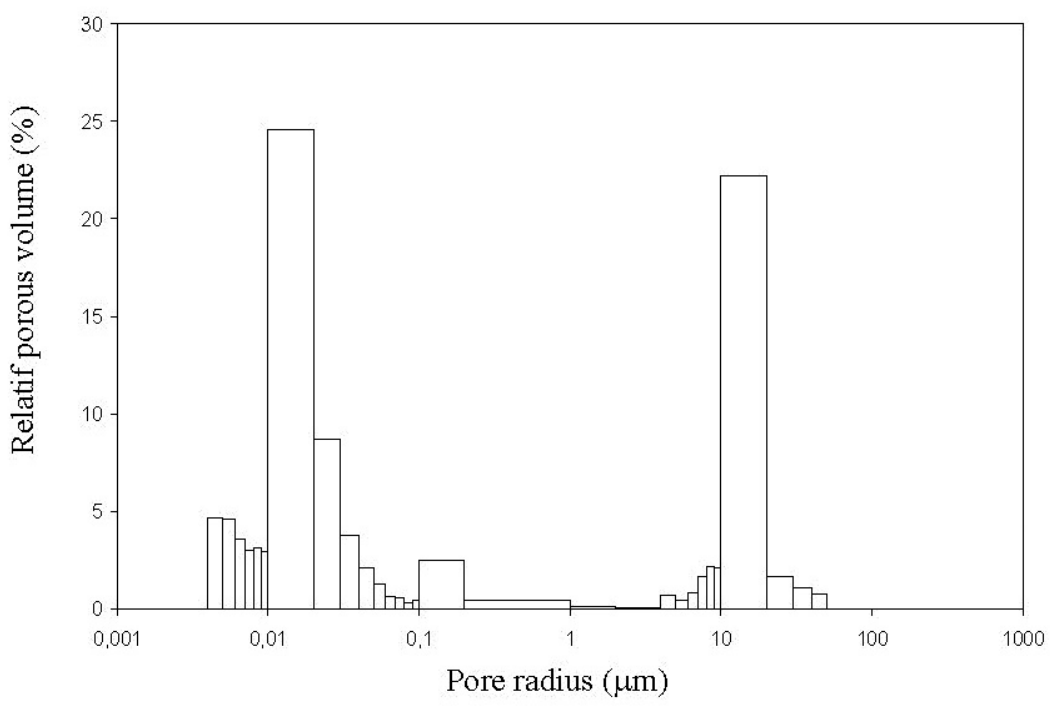

Figure 2: Pore size distribution of olive wood.

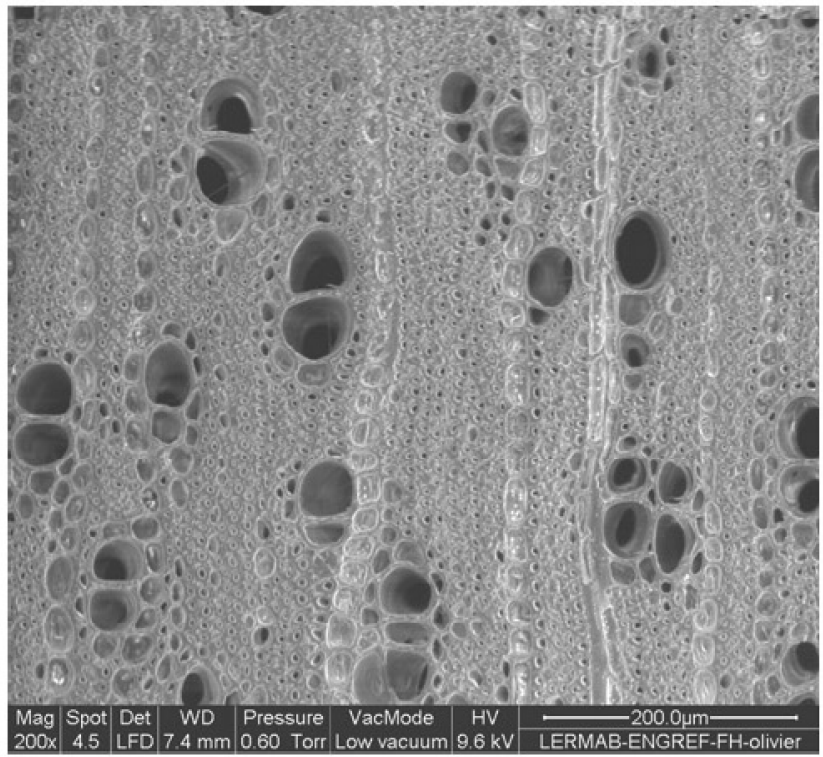

Figure 3: Electronic microscopy of transversal section for virgin olive wood

\section{Carbonized olive wood}

Figure 4 shows the cumulative pore volume for different olive wood samples carbonized at fixed temperatures between 473 and $623 \mathrm{~K}$. The cumulative pore volume increases with the final temperature of carbonization. This variation is very large since the cumulative pore volume changes from 500 $\mathrm{mm}^{3} \cdot \mathrm{g}^{-1}$ for the initial olive wood sample to $4300 \mathrm{~mm}^{3} \cdot \mathrm{g}^{-1}$ for the olive wood carbonized at $623 \mathrm{~K}$. In the same time, the olive wood samples loses $70 \%$ of its mass (figure 1). A large increase of the cumulative pore volume between $523 \mathrm{~K}$ and $548 \mathrm{~K}$ can be observed. In this temperature range, the mass loss is about $54 \%$. 


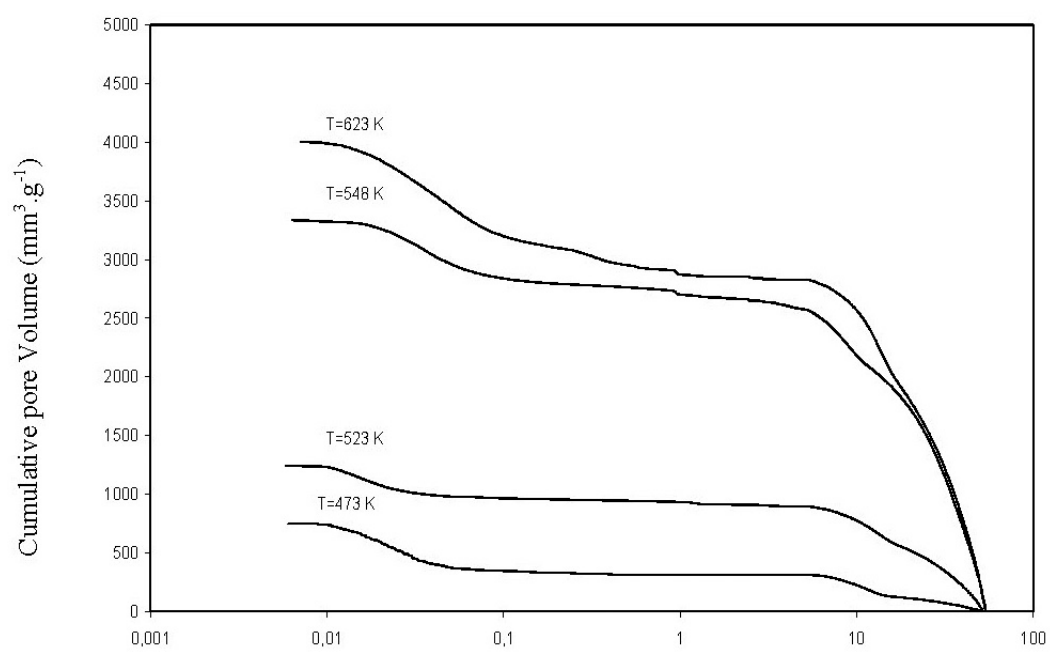

Pore radius $(\mu \mathrm{m})$

Figure 4: Cumulative pore volume distribution versus of the pore radius at different fixed temperature of carbonization.

Pore size classes distribution at different fixed carbonization temperatures are plotted on figures $5 \mathrm{a}$ to $5 \mathrm{e}$. Class III moves towards the high values of pores radius and becomes the dominant class in the porous distribution. Moreover, class I decreases when the carbonization temperature increases and conducts to the existence of class II which appears during the thermal treatment. The volume fraction of the three classes of the pore radius is represented on figure 6 as a function of the carbonization temperature. The main pore sizes characteristics of the olive wood samples obtained by porosimetry measurements are summarized on table 3 . Total porosity increases with the final carbonization temperature of olive wood and its apparent density logically decreases. The values of the porosity observed from the temperature $T=548 \mathrm{~K}$ are certainly too high because the values of the apparent density obtained with the porosimeter device Pascal 140 are too low. Indeed, during the filling the dilatometer, the mercury penetrates in the pores of the carbonized sample the radius of which are between 30 and $50 \mu \mathrm{m}$ correspond in to a pressure of $380 \mathrm{kPa}$.

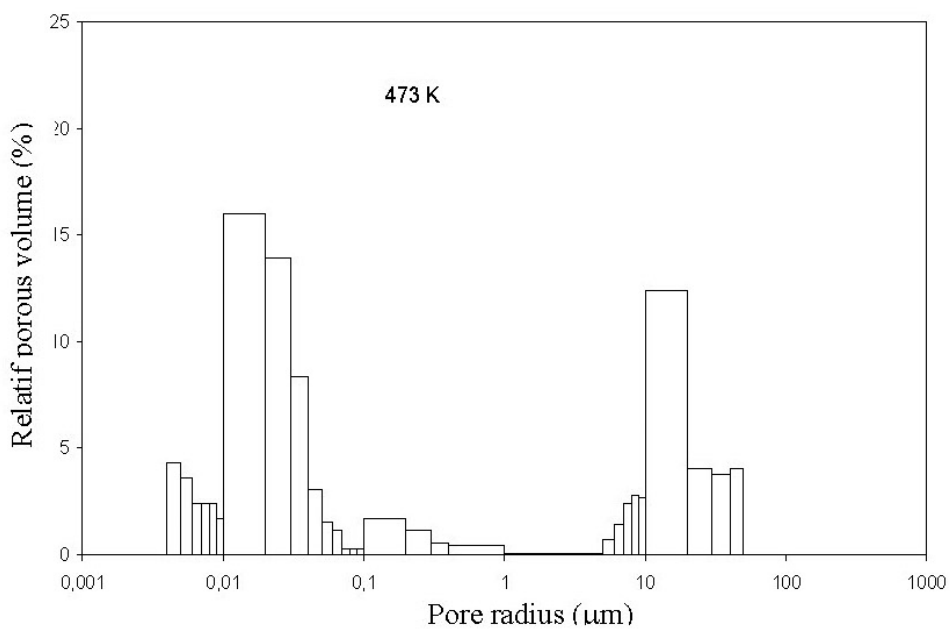

Figure 5a: Pore size distribution for wood pyrolysed at $T=473 \mathrm{~K}$. 


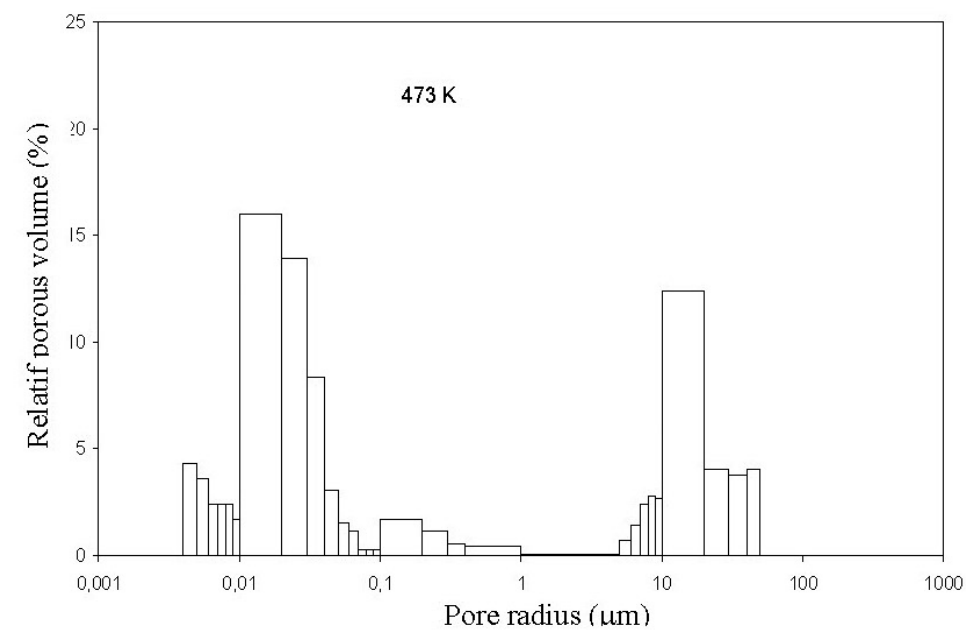

Figure 5b: Pore size distribution for wood pyrolysed at $T=523 \mathrm{~K}$.

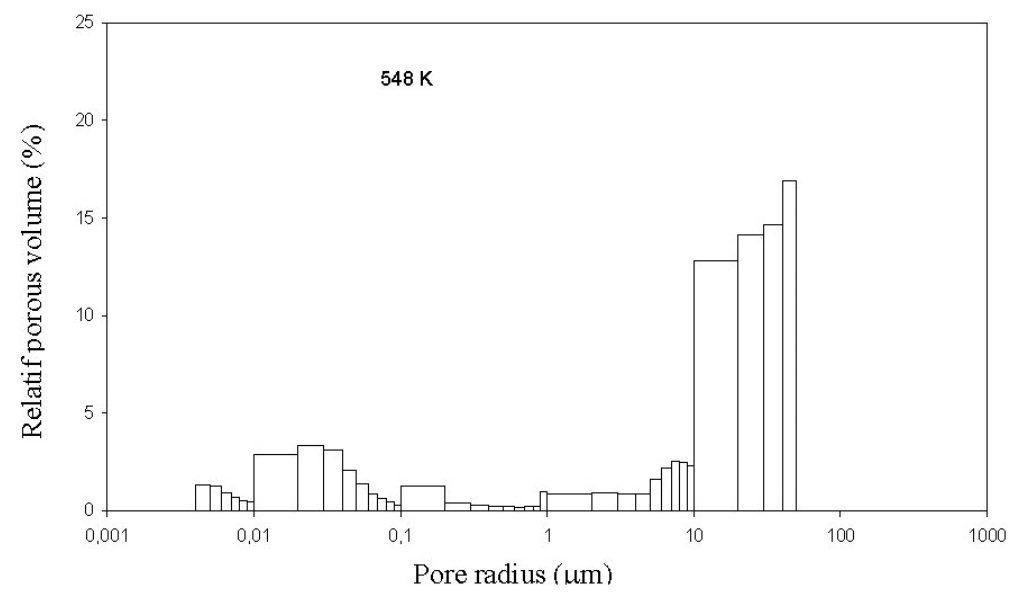

Figure 5c: Pore size distribution for wood pyrolysed at $T=548 \mathrm{~K}$.

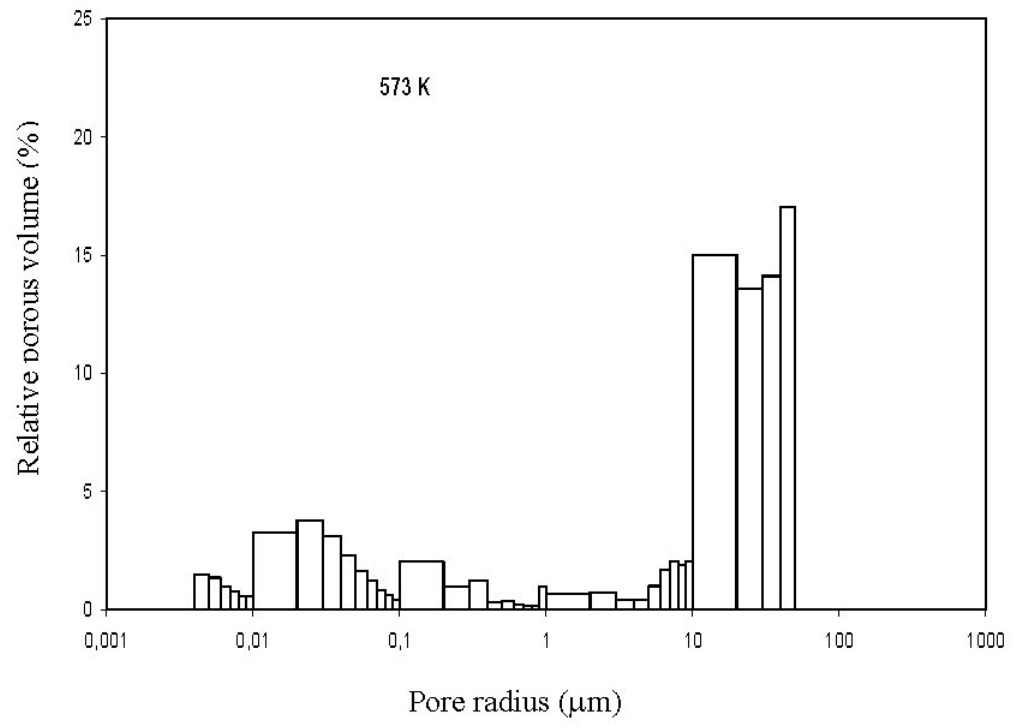

Figure 5d: Pore size distribution for wood pyrolysed at $T=573 \mathrm{~K}$. 


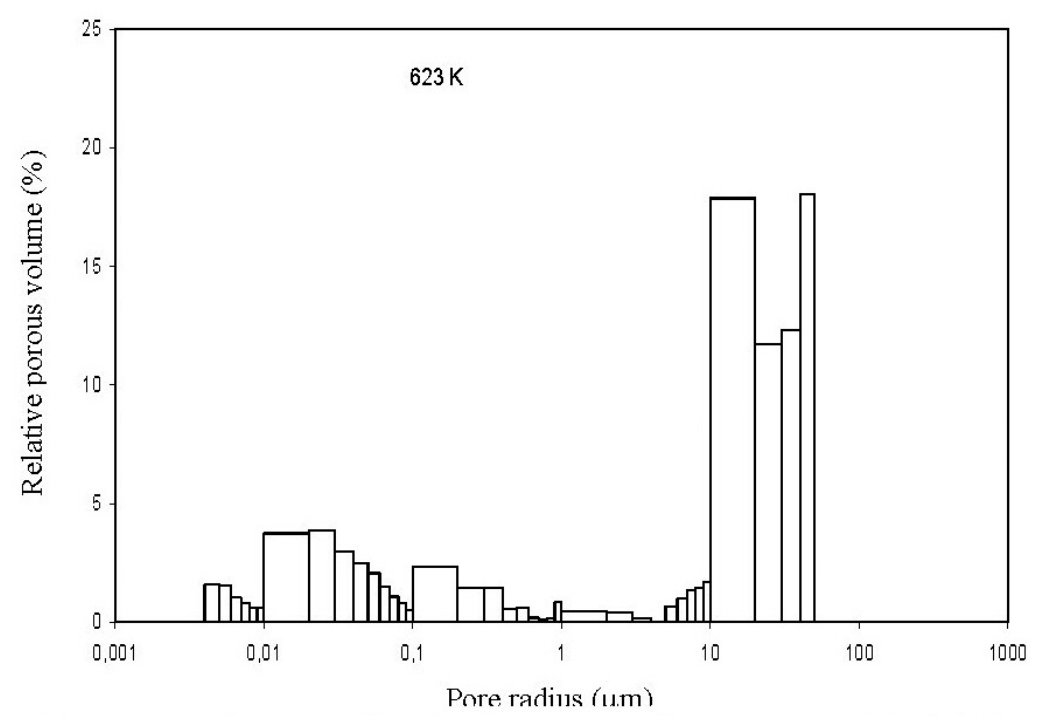

Figure 5e: Pore size distribution for wood pyrolysed at $T=623 \mathrm{~K}$

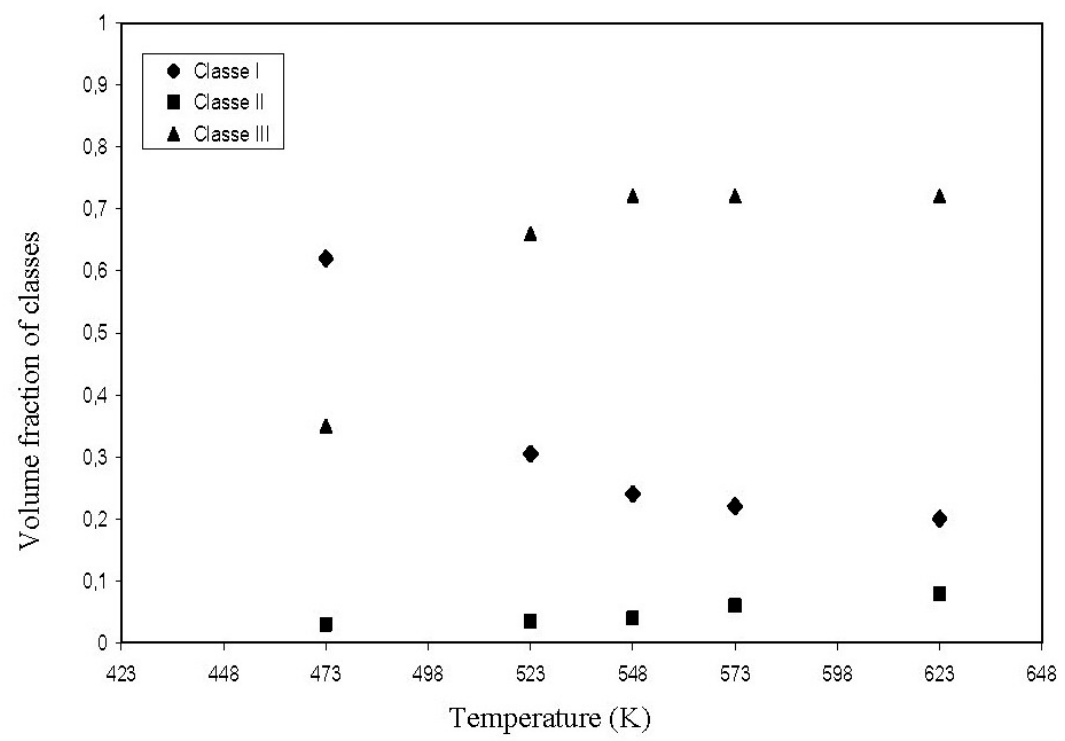

Figure 6: Porous volume fraction evolution of the three classes of pores versus the carbonization temperature. 
Table 3: Porosimetry parameters of olive wood carbonized at different fixed temperatures.

\begin{tabular}{|l|c|c|c|c|c|}
\hline Temperature $T(\mathrm{~K})$ & 473 & 523 & 548 & 573 & 623 \\
\hline Cumulative total volume VPT $\left(\mathrm{mm}^{3} / \mathrm{g}\right)$ & 748 & 1241 & 3336 & 3500 & 4002 \\
\hline Mean pore diameter $\bar{d}(\mu \mathrm{m})$ & 0.102 & 24 & 38 & 32 & 34 \\
\hline Total porosity $\varepsilon(\%)$ & 50 & 56.1 & 84 & 87.5 & 89.7 \\
\hline Apparent density $\rho_{a}\left(\mathrm{~kg} \cdot \mathrm{m}^{-3}\right)$ & 669 & 523 & 263 & 250 & 224 \\
\hline Real density $\rho_{s}\left(\mathrm{~kg} \cdot \mathrm{m}^{-3}\right)$ & 1338 & 1193 & 1644 & 2000 & 2185 \\
\hline
\end{tabular}

The mean observation concerning the porosity values of the carbonization samples is the large variation of the porosity between the samples carbonized at 523 and the ones at $548 \mathrm{~K}$.

To explain the increase of the porosity, we have observed the sample before and after carbonization at $548 \mathrm{~K}$ with an environmental electronic microscope (unless metallization). Figures $7 \mathrm{a}$ and $7 \mathrm{~b}$ concern the same zone of an annual ring respectively for the virgin and carbonized olive wood. The transversal section does not show any modification of the anatomic structure when the mass loss is about $54 \%$. We only observe the shrinkage of the sample in the tangential direction $(15.21 \%)$ and radial direction $(9 \%)$. The increase of global porosity may be due to the thinning and cracking of the cell walls, hardly visible by microscopy.

For this reason, to try to interpret correctly the porosimetry measurements and the high variation observed at $548 \mathrm{~K}$, we use a kinetic model developed in a previous article [Grioui et al. 2006].

To represent accuratly the kinetic of olive wood carbonization in an inert atmosphere, it is necessary to divide wood material in three pseudo components for which the degradation temperature and the nature of the products formed are different. These pseudo components noted $\mathrm{A}_{1}, \mathrm{~A}_{2}$ and $\mathrm{A}_{3}$ can not be exactly identified as hemicelluloses, cellulose and lignin material [Grioui et al. 2006]. The mass fractions of these three pseudo components are respectively $\alpha_{1}, \alpha_{2}$ and $\alpha_{3}=1-\alpha_{1}-\alpha_{2}$.

(a)

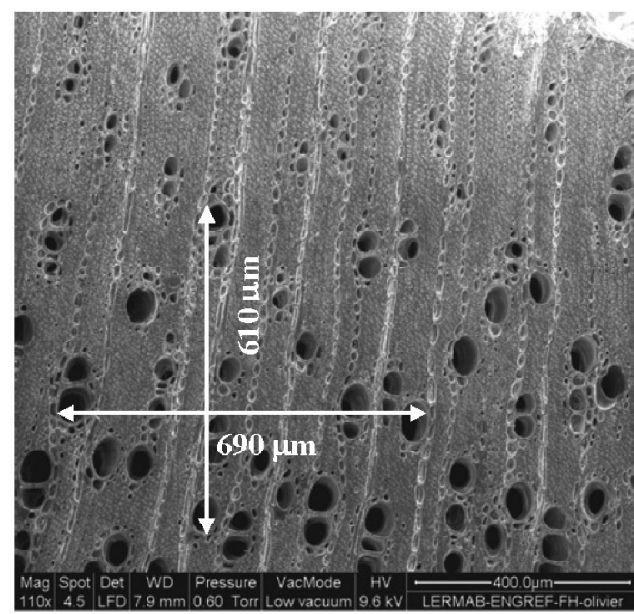

(b)

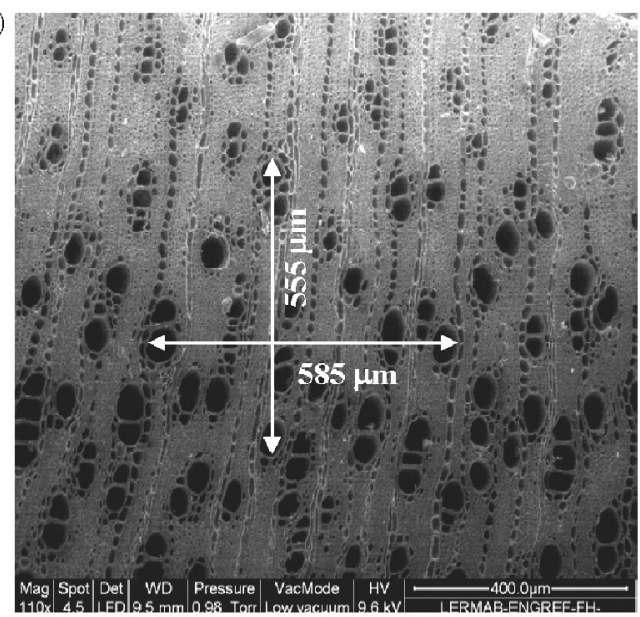

Figure 7: Electronic microscopy transversal section of virgin wood (a); carbonized wood at $548 \mathrm{~K}(\mathrm{~b})$. 
The stoechiometries of carbonization of these pseudo components are assumed to be the following ones:

$$
\begin{array}{ll}
A_{1}\left(1^{\text {st }} \text { pseudo component of wood }\right) \longrightarrow & G_{1} \text { (gas) } \\
A_{2}\left(2^{\text {nd }} \text { pseudo component of wood }\right) \longrightarrow & \left.\gamma_{2} C_{2} \text { (charcoal }\right)+G_{2} \text { (gas) } \\
A_{3}\left(3^{\text {rd }} \text { pseudo component of wood }\right) \longrightarrow & \beta B \text { (intermediate solid })+G_{3} \text { (gas) } \\
B \text { (intermediate solid }) \longrightarrow & \left.\gamma_{3} C_{3} \text { (charcoal }\right)+G_{4} \text { (gas) }
\end{array}
$$

For the first two ones, the thermal degradation takes place in a single reaction stage giving a not degradable solid residue $C_{2}$ and gas products $\left(G_{1}\right.$ and $\left.G_{2}\right)$ (Eq. (6) and (7)). For the third pseudo component, the thermal degradation takes place in two consecutive stages (Eq. (8) and (9)). The first stage conducts to an intermediate product (B) comparable to a solid (large hydrocarbon molecule) and gases; the second stage transforms the intermediate product $(\mathrm{B})$ in a not degradable solid $\left(\mathrm{C}_{3}\right)$ and gas products. The mass fractions of the intermediate product $(\beta)$ and the not degradable solid $\left(\gamma_{3}\right)$ depend on the temperature. This kinetic model permits to represent very well the variation of the total reduced residual mass of olive wood during the carbonization for the whole studied temperatures (continuous curves on the figure 1).

Figure 8 represents the variation of the reduced residual mass of the solid components $A_{1}, A_{2}$ and $\mathrm{A}_{3}, \mathrm{C}_{2}, \mathrm{C}_{3}$ and $\mathrm{B}$ of the carbonized samples, at the end of the isothermal stage, for each fixed temperature. $\mathrm{A}_{1}$ is totally degraded at $498 \mathrm{~K}$ and at $523 \mathrm{~K}, \mathrm{~A}_{2}$ is strongly degraded then the degradation of the pseudo component $\mathrm{A}_{3}$ starts. Between 523 and $548 \mathrm{~K}$, the degradation rate of the pseudo component $\mathrm{A}_{3}$ becomes high and the strong mass loss of the pseudo component $\mathrm{A}_{3}$ explains the increase of the porosity of carbonized sample. The cell walls becomes thin and fissured. The penetration of the mercury probably induces the cracking of the walls and permits to understand the development of large pores as observing during the porosity measurements (figure $5 \mathrm{~b}$ to $5 \mathrm{e}$ ).

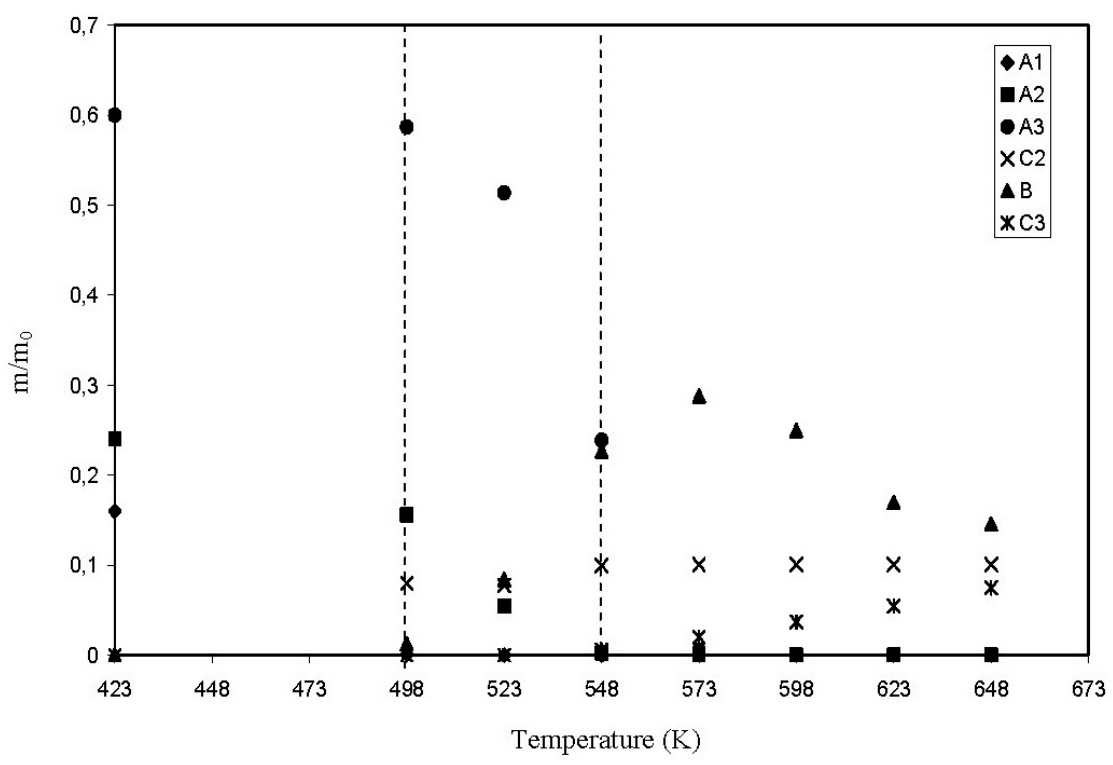

Figure 8: Reduced mass solid components $A_{1}, A_{2}, A_{3}, C_{2}, C_{3}$ and $\mathrm{B}$ versus the studied carbonization temperatures. 


\section{CONCLUSIONS}

The thermal degradation of olive wood during carbonization notably increases the global porosity of the carbonized samples. The largest variation is observed when the temperature of degradation varies between 523 and $548 \mathrm{~K}$ which correspond to a high degradation rate of the pseudo component $\mathrm{A}_{3}$ whereas the pseudo components $\mathrm{A}_{1}$ and $\mathrm{A}_{2}$ are totally degraded. In this conditions, the cell walls becomes thin and fissured and during porosimetry measurements the penetration of the mercury induces the breaking of the walls and then the formation of the pores, the radius of which are larger to $30 \mu \mathrm{m}$. The environmental SEM observations confirm that the carbonization does not change the structure of olive wood and only the thickness and cracking of the cell walls.

\section{REFERENCES}

Abell, A.B.; Willis, K.L.; Lange, D.A. 1999. Mercury intrusion porosimetry and image analysis of cement-based materials. Journal of Colloid and Interface Science 211: 39-44.

Blankenhorn, P. R.; Barnes, D. P.; Kline, D. E.; Murphey, W. K. 1978. Porosity and pore size distribution of Black Cherry carbonized in an inert atmosphere. Wood Science 11(1):23-29

Clarkson, C.R.; Bustin, R.M. 1999. The effect of pore structure and gas pressure upon the transport properties of coal: a laboratory and modeling study. 1. Isotherms and pore volume distributions. Fuel 78: $1333-1344$

Friesen, W.I.; Ogunsola, O.I. 1995. Mercury porosimetry of upgraded western canadian coals. Fuel 74(4): 604-609

Fujii, T.; Suzuki, Y.; Kuroda, N. 1997. Bordered pit aspiration in the wood of Cryptomeria Japonica in relation to air permeability. IAWA J. 18 (1): 69-76,

Ghelmeziu, N. G.; Suciu, P.N. 1959. Identificared lemnului. Editura Technica 194.

Gregg, S. J.; Sing, K. S. W. 1982. Adsorption, surface area. Academic Press, Inc. London, 173-

Grioui, N.; Halouani, K.; Zoulalian, A.; Halouani, F. 2006. Thermogravimetric analysis and kinetics modeling of isothermal carbonization of olive wood in inert atmosphere. Thermochimica Acta 440: 23-30.

Heui-Seol, R.; Suk, W. Y. 2004. Acoustic diagnosis for porous medium with circular cylindrical pores. Journal of Acoustical Society of America 115 (3): 1114-1124.

Klose, W.; Schinkel, A. 2002. Measurement and modelling of the developement of pore size distribution of wood during pyrolysis. Fuel Processing Technology 77-78, 459-466.

Koufopanos, C.A.; Maschio, G.; Lucchesi A. 1989. Kinetic modelling of the pyrolysis of biomass and components. Canadian Journal of Chemical Engineering 67: 75-84

Kumar, M.; Gupta, R. C. 1993. Influence of carbonization conditions on physical properties of Acacia and Eucalyptus wood chars. Transactions of the Indian Institute of Metals 46 (6): 345-352 
Laurent, P. ; Trenard, Y. 1981. Etude et observations d'un bois de hêtre stratifié densifié. Holforschung 35: 27-32

Leofanti, G.; Padovan, M.; Tozzola, G.; Venturelli, B. 1998. Surface area and pore texture of catalysts. Catalysis Today 41(1-3): 207-219

Leon, C. A. 1998. New perspectives in mercury porosimetry. Advances in Colloid and Interface. Science 76-77: 341-372

Mackay, D.M.; Roberts, P. V. 1982. The influence of pyrolysis conditions on yield and mic lignocellulosic chars. Carbon 20: 95-105.

Moscou, L.; Lub, S. 1981. Practical use of mercury porosimetry in the study of porous solids. Powder Technology 29: 45-52

Randal, T. B.; Blankenhorn, P. R. 1982. Calorific and porosity development in carbonized wood. Wood Science 15(1):19-28.

Rigby, S. P.; Edler, K. J. 2002. The influence of mercury contact angle, surface tension, and retraction mechanism on the interpolation of mercury porosimetry data. Journal of Colloid and Interface Science 250: 175-190

Rigby, S.P.; Fletcher, R. S.; Riley, S. N. 2003. Determination of the cause of mercury entrapment during porosimetry experiments on sol-gel silica catalyst supports. Applied Catalysis A: General 8526: $1-13$

Salmas, C.; Androutsopoulos, G. 2001. Mercury porosimetry: Contact angle hysteresis of materials with controlled pore structure. Journal of Colloid and Interface Scienc, 239: 1758-189

Spiter, Z. 1981. Mercury porosimetry and application to the analysis of coal pore structure. Powder Technology 29: 177-186

Thunman, H.; Leckner, B. 2002. Thermal conductivity of Wood- Models for different stages of combustion. Biomass and Bioenergy 23(1): 47-54,

Trenard, Y. 1980. Comparaison et interprétation de courbes par porosimétrie au mercure sur diverses essences de bois. Holforschung 34 : 139-146.

Van Brakel, J.; Modry, S.; Svatà, M. 1981. Mercury porosimetry: state of the art. Powder Technology 29: 1-12.

Washburn, E. W. 1921. The dynamics of capillary flow. The Physical Review 17: 273-283. 